phase was added, and the cultures were rotated at $37^{\circ} \mathrm{C}$. for one to two months with no further attention. On Nov. 12 one culture showed fibroblastic outgrowth and was transferred. As outgrowth occurred in other tubes, further transfers were made. The 'fibroblasts' grew actively, and several hundred subcultures were made during the ensuing months.

The fibroblastic cultures were transferred and fed in the routine manner, and gradually during a period of a few months reverted to the original strain pattern of epithelial carcinoma. The cells reverted during experiments done in January and February. By March and April the cells had completely reverted to type, after being dormant (looking like thin threads) or living as transitional fibroblasts for six to eight months. This process of converting dormant fibre. blastic cells to active sheet-forming cells has been repeated regularly since then.

The 'hibernating' fibroblastic cultures accumulate large masses of fat.

The small, dormant, thread-like refractile cells in viable cultures which have received no media or attention for six to ten months might be considered a paramorphic type of cell, such as Hadfield ${ }^{1}$ has discussed.

Apart from these fundamental observations, the cultures are of practical importance, as they constitute a large supply of stock material that requires no attention or media when not in use. The chance of losing the strain through accidental contamination is also lessened.

The fibroblastic cells appear to be resistant to agents that cause destruction of the epidermoid carcinomatous forms, such as the polio virus (Brunhilde strain obtained from Dr. Herdis von Magnus, State Serum Institute, Copenhagen) and chemical substances.

A more detailed report of the $A$ and $A f$ cells is in preparation.

Audrey Fjelde

Tuberculosis Immunization Research Centre, Statens Seruminstitut, Copenhagen. Nov. 4. ${ }^{1}$ Hadffeld, G., Brit. Med. J., ii, 607 (Sept. 11, 1954). See also ibid.,

\section{Biosynthesis of Hyaluronate}

THe formation of hyaluronate by strains of Lancefield Group $A$ and $C$ streptococci growing in ordinary laboratory media was first shown by Kendall, Heidelberger and Dawson ${ }^{1}$ and by Seastone ${ }^{2}$. More recently, it has been demonstrated ${ }^{3}$ that the glucosamine and glucuronic acid moieties of hyaluronate are formed from glucose by cultures of these microorganisms, without rearrangement of the carbon skeleton.

Previously we had reported ${ }^{4}$ that glutamine specifically stimulates the formation of bound glucosamine, as hyaluronic acid, by washed preparations of group $A$ streptococci incubated at $35^{\circ}$ in a simple buffered glucose - salt solution of the following composition : $0.08 M$ sodium $\beta$ glycerophosphate (anhydrous) $0.028 M$ glucose, $0.02 M$ magnesium chloride, $0.025 M$ inorganic phosphate buffer $p H 7 \cdot 0$; the final $p H$ of this mixture is $7 \cdot 0$. We now suggest, on the basis of further work using washed preparations, that the pathway for the synthesis of the glucosamine in hyaluronate by streptococci is : (a) $\mathrm{NH}_{4}^{+}+$glutamic acid $\rightarrow$ glutamine;

(b) Glutamine + glucose (or hexose derivative) $\rightarrow$ bound glucosamine + glutamate.

Evidence for this suggestion is as follows. (1) Glutamine or ammonium glutamate stimulates the formation of bound hexosamine in aged preparations of washed cells, but neither ammonia nor glutamic acid is separately effective: (2) Methionine sulphoxide, known to inhibit glutemine synthesis from ammonium glutamate in other systems ${ }^{5}$, prevents synthesis of bound glucosamine in the presence of ammonium glutamate but not in the presence of glutamine. (3) A close relationship exists between the amount of glutamine or ammonium glutamate taken up by the cells and the bound glucosamine formed; at lower levels of nitrogen source the amount of bound glucosamine-nitrogen appearing approximates to half the total nitrogen supplied. (4) A cell-free extract of streptococci supplemented by $10^{-3} M$ adenosine triphosphate, $0.022 M$ cysteine, $0.025 M$ inorganic phosphate, $0.028 M$ glucose and $0.02 M$ magnesium ion formed glucosamine from glutamine but not from ammonium glutamate ; it is not known whether this hexosamine is free or bound into mucopolysaccharide. (5) Very high (80-100 per cent) conversion of nitrogen-15 from ammonium ion into bound glucosamine nitrogen of hyaluronate has been shown in the presence of unlabelled glutamate.

This work, together with the similar observations of Leloir and Cardini ${ }^{8}$ for the formation of glucosamine by Neurospora extracts, suggests that the above pathway is a general one for the synthesis of hexosamine, at least in micro-organisms. Full details of this work will be published elsewhere.

\section{A. LOWTHER}

H. J. Rogers

National Institute for Medical Research, The Ridgeway, Mill Hill, London, N.W.7. Nov. 8.

1 Kendall, F. F., Heidelberger, M., and Dawson, M. H., J. Biol. Chem., 118, 61 (1937)

Seastone, C. V., J. Exp. Med., 70, 361 (1939).

${ }^{3}$ Roseman, S., Moses, F. E., Ludoweig, J., and Dorfman, A., J. Biol. Chem., 203, 213 (1953). Roseman, S., Ludoweig, J., Moses, F. E., and Dorfman, A., J. Biol. Chem., 206, 665 (1954). Topper, Y. J., and Lipton, M. M., J. Biol. Chem., 208, 135 (1953).

4Lowther, D. A., and Rogers, H. J., Biochem. J., 53, xxxix (1953).

' Waelsch, H., Owades, P., Miller, H. K., and Borek, E.. J. Biol. Chem., 166, 273 (1946)." Elliott', W. H., Biochem. J., 49, 106 (1951). Elliott, W. H., and Gale, E. F., Nature, 161, 129 (1948). Mcilwain, Leloir I F. and Cardini, C. F., Biochim et Biophys. Acta, 12, 15 (1953).

\section{Utilization of Sulphate Ion by Fibroblasts in the Quartz Focus}

MUCOPOLYSACCHARIDES are abundant in healing: wounds and other sites where collagen is forming, and Meyer ${ }^{1}$ postulated their production in large quantities by fibroblasts. The mast cell has been credited with producing 'ground substance's or hyaluronic acid ${ }^{3}$; but Bunting and Bunting ${ }^{4}$ recently reviewed much of the evidence for the source of mucopolysaccharide in fibroplasia and came to the conclusion that an origin from 'fibrocytes' seemed probable but not conclusive. Klemperer ${ }^{6}$ expressed similar views : his objections were based largely on the non-specificity of the periodic acid-Schiff method for mucopolysaccharides. Gersh and Catchpole ${ }^{6}$ had postulated previously a secretory cycle in 